\title{
Limited myelotomy for the treatment of intractable cancer pain
}

\author{
PHILIP L GILDENBERG, RICHARD M HIRSHBERG
}

From The University of Texas Medical School at Houston, and the Division of Neurosurgery, St Joseph Hospital, Houston, Texas, USA

SUMMARY In midline myelotomy a small mechanical or radiofrequency lesion was made at the centre of the spinal cord at a single segment at the thoracolumbar junction or at $\mathrm{C}_{1}$. This procedure was used for the management of cancer pain in 20 patients, in four of whom it was combined with unilateral cordotomy. Of 14 patients with myelotomy alone at the thoracolumbar junction $10(71.5 \%)$ had satisfactory relief of pain, with no complications or untoward sideeffects.

A new procedure is described, in which midline myelotomy is limited to a single segment for the treatment of midline pelvic pain from cancer.

Both lateral spinothalamic tractotomy and commissural myelotomy ${ }^{1-5}$ are accepted techniques for the treatment of intractable pain, particularly after malignancy. However, cordotomy has proved to be disappointing for pelvic or midline pain, and pain may return even after initial good relief. Classical commissural myelotomy involves a relatively extensive spinal cord section and may be followed by impairment of function of the lower extremities for several weeks. ${ }^{124}$ It has been reported that pain relief often exceeds the amount of analgesia produced after commissural myelotomy. ${ }^{1245}$

Both the recurrence of pain after cordotomy, even with excellent analgesia, and the relief of pain without analgesia in myelotomy suggest the existence of a spinal cord pathway in addition to the lateral spinothalamic tract. ${ }^{36}$ These observations led to the hypothesis that such a pathway ascends near the central canal of the spinal cord. ${ }^{36-11}$

\section{Method}

Limited surgical lesions were made in the centre of the cord at the thoracolumbar junction to interrupt that hypothetical pathway for the treatment of intractable pain

Address for reprint requests: Philip L Gildenberg, MD, PhD, 6560 Fannin, 1530, Houston, Texas 77030, USA.

Received 22 November 1982 and in revised form 19 July 1983. Accepted 2 August 1983 in patients with pelvic malignancy under general anaesthesia with the patient in the prone position. $A T_{9}$ or $T_{10}$ laminectomy was performed, in order to expose the spinal cord at approximately the thoracolumbar junction. The $5 \mathrm{~mm}$ segment of the midline of the spinal cord with the least overlying vasculature was selected through the operating microscope. A small midline incision was made in the pia, and, with a blunt microdissector, the midline of the spinal cord was gently dissected for a length of 5 to $7 \mathrm{~mm}$ to a depth of $6 \mathrm{~mm}$ (fig). Ordinarily, the pial fold of the anterior median fissure could be palpated and the dissector was moved to and fro repeatedly at that depth.

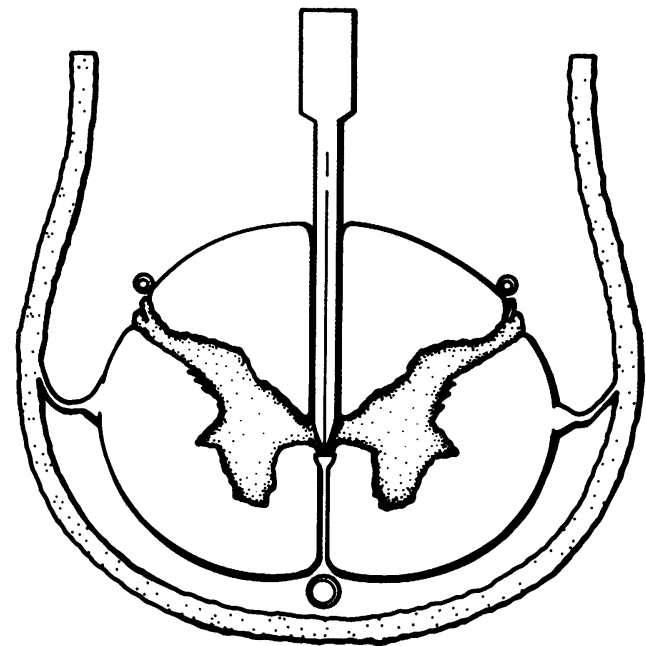

Fig The dissector is inserted through the midline of the spinal cord so that a mechanical lesion is made around the area of the central canal. 
Table Procedures and results in 20 patients

\begin{tabular}{lllll}
\hline & Excellent & Good & Fair & Poor \\
\hline 12 patients mechanical \\
$\begin{array}{c}\text { limited myelotomy } \\
2 \text { radiofrequency }\end{array}$ & 5 & 3 & 2 & 2 \\
$\quad \begin{array}{c}\text { limited myelotomy } \\
\overline{14} \text { limited myelotomy }\end{array}$ & $\overline{6}$ & $\overline{4}$ & $\overline{2}$ & $\overline{2}$ \\
$2 \begin{array}{c}\text { upper cervical } \\
\text { myelotomy }\end{array}$ & $\mathbf{4}$ & 1 & 1 \\
$* \begin{array}{c}\text { myelotomy plus } \\
\text { cordotomy }\end{array}$ & 2 & 1 & 1 \\
\hline
\end{tabular}

*Two patients had postoperative leg weakness.

\section{Results}

Twenty patients had limited myelotomies using various types of procedures. In 12 patients, the lesion was made mechanically with a microprobe. Two patients had an identical procedure, except the lesion was made with a radiofrequency current rather than mechanically with a percutaneous cervical cordotomy electrode.

Four patients had myelotomy for pelvic pain plus unilateral cordotomy for hip pain secondary to destructive bony metastases, the type of hip pain which classically responds well to cordotomy. Two patients had a limited myelotomy at the $C_{1}$ level, with mechanical lesions similar to the radiofrequency lesions produced stereotactically by Hitchcock ${ }^{67}$ and Schvartz $\mathrm{z}^{3}$ " for pulmonary carcinoma with chest and arm pain.

Results were considered excellent if virtually no pain remained, and good if the patient had significant improvement and no longer required narcotics stronger than codeine, but still had some remaining pain. Patients were classified as fair if they reported improvement, but not enough either to increase activity or decrease medications, and were classified as poor if there was no change in their pain. No patient became worse. Patients were followed until death 2 to 13 months after myelotomy, or 6 months to 2 years in survivors. (table).

Of the 12 patients who had the classical mechanical limited myelotomy, eight had satisfactory results, five being excellent and three with mild residual pain. Two patients had no pain relief at all and two had only slight relief. Those patients who had relief of pain maintained that relief throughout the duration of follow-up, although several had pain from new metastases higher in the body.

The two patients who had radiofrequency lesions at the lumbosacral junction of the spinal cord had satisfactory pain relief, one with no residual pain and the other with considerable improvement of pain. There was no demonstrable sensory loss, no weakness, and no loss of sphincter control.

Of the four patients who underwent myelotomy combined with cordotomy, two had good relief of pain, one fair, and one had no pain relief at all. Unfortunately, one of the patients with a good result and one of the patients with a fair result had significant weakness of the leg ipsilateral to the cordotomy, which would not have been anticipated with either myelotomy or cordotomy alone, and this has discouraged us from performing any more such combined lesions at a single operation.

Of the two patients with mechanical lesions at the $C_{1}$ level, one had good relief of pain, but a later recurrence of pain, and the other had only slight improvement.

\section{Discussion}

Classical lumbosacral commissural myelotomy is designed to interrupt the lateral spinothalamic fibres as they decussate in the midline by separating the spinal cord longitudinally in the midline, following which one would anticipate a loss of pain sensation in the involved segments. This procedure was first performed by Amour ${ }^{12}$ and has had sporadic popularity since then. ${ }^{12413-16}$ It has been made safer and more reliable by the use of the operating microscope, which has prompted some recent resurgence in its use. ${ }^{12}$ After operation, however, many of these patients experience paraesthesias and change of body consciousness in the lower body, as well as loss of proprioception in the lower extremities, which makes walking difficult. Fortunately, these symptoms generally disappear within two to three weeks, when the patient may be pain-free and symptomfree.

Several authors have indicated in their enthusiastic support of this procedure that the patient's relief of pain often exceeds the amount of analgesia, ${ }^{1245}$ which has led to the consideration that there may be a coincidental interruption of an ascending pathway by the midline lesion. Of particular interest is a report by Wertheimer and Lecuire, ${ }^{5}$ who made a midline incision only $4 \mathrm{~mm}$ deep at the fourth to sixth thoracic vertebral levels. They reported a $65 \%$ success rate, and usually noted preservation of pain and temperature sensation. At necropsy there was preservation of the lateral spinothalamic tract, although they continued to attribute their result to interruption of the commissure.

Hitchcock ${ }^{6-8}$ and Schvartz ${ }^{310} 11$ concluded that an extralemniscal pathway lies in the centre of the cord at the cervicomedullary junction, and they produce stereotactic lesions in that area for treatment of pain throughout the body. ${ }^{3681011}$ Schvartz $^{10}$ suggested 
that this previously undescribed pathway ascends throughout the centre of the cord, and it is probably continuous with the medullary pathway described by Collins and Randt. ${ }^{1617}$

Similar considerations have led another surgeon to perform the operation of Hitchcock and Schvartz by open cervical myelotomy at the $\mathrm{C}_{1}$ level (King, JS: personal communication, 1979). He had 10 patients in his series, with a $65 \%$ success rate, two in collaboration with one of us (PLG). Another group has been making limited radiofrequency lesions at various thoracic levels with results similar to ours. ${ }^{15}$

The precise location and nature of this hypothetical pathway has not yet been determined by anatomical techniques, probably because it consists of many diffuse multisynaptic fibres. It is possible that the pathway under question ascends in the most anterior portion of the dorsal columns, where there is a dense bundle of fibres forming a compact bundle. It is likely that this extralemniscal pathway is the same that ascends in the vicinity of the central canal at midbrain levels. ${ }^{18-20}$

Sourek $^{4}$ presents another possible explanation for the effectiveness of myelotomy in relieving pain, even in the absence of analgesia. He notes that there is invariably minimal damage to the dorsal funiculi in addition to the damage to the decussating spinothalamic tract fibres, and hypothesises that this combined lesion to two phylogenetically and functionally different fibre systems may distort the normal time and space pattern of impulses in order to eliminate the perception of the pathological pain.

The authors are grateful to Drs John S Stehlin, P de Ipolyi and P Greef of St Joseph Hospital, and Drs Lester L Hoaglin, Jr, Barthel Barlogie, and Harry Price of Hermann Hospital, for referral of these patients.

\section{References}

' Cook AW, Kawakami Y. Commissural myelotomy. J Neurosurg 1977;47:1-6.
${ }^{2}$ King RB. Anterior commissurotomy for intractable pain. J Neurosurg 1977;47:7-11.

${ }^{3}$ Schvartz JR. Spinal cord stereotactic techniques re trigeminal nucleotomy and extralemniscal myelotomy. Appl Neurophysiol 1978;41:99-112.

${ }^{4}$ Sourek K. Commissural myelotomy. J Neurosurg 1969;31:524-7.

${ }^{5}$ Wertheimer P, Lecuire J. La myelotomie commissurale posterieure. A propos de 107 observations. Acta Chir Belg 1953;52:568-74.

- Hitchcock ER. Stereotactic cervical myelotomy. J Neurol Neurosurg Psychiatry 1970;33:224-30.

${ }^{7}$ Hitchcock E. Stereotaxic spinal surgery. A preliminary report. J Neurosurg 1969;31:386-92.

${ }^{8}$ Hitchcock ER. Stereotaxis of the spinal cord. Conf Neurol 1972;34:299-310.

${ }^{9}$ Hitchcock E. Stereotactic myelotomy. Proc $R$ Soc Med 1974;67:771-2.

${ }^{10}$ Schvartz JR. Stereotactic extralemniscal myelotomy. $J$ Neurol Neurosurg Psychiatry 1976;39:53-7.

" Schvartz JR. Functional exploration of the spinomedullary junction. Acta Neurochir 1977;Suppl. 24:179-85.

${ }^{12}$ Armour D. Surgery of the spinal cord and its membranes. Lancet 1927;1:691-7.

${ }^{13}$ Broager B. Commissural, sagittal myelotomy for pains in the lower half of the body of 22 patients. Acta Neurol Scand 1972;48:258-9.

14 Putnam TJ. Myelotomy of the commissure: A new method of treatment for pain in the upper extremities. Arch Neurol Psychiatry 1934;32:1189-93.

is Sourek K. Central thermocoagulation of the cord for relief of intractable pain (abstr.). Neurological Surgery (Proc World Fed Neurosurg Soc Munich). Stuttgart: Georg Thieme, 1981: 66.

${ }^{16}$ Collins WF, Randt CT. Evoked central nervous system activity relating to peripheral unmyelinated or ' $C$ ' fibers in cat. $J$ Neurophysiol 1958;21:345-52.

${ }^{17}$ Collins WF, Randt CT. Fiber size and organization of afferent pathways. Arch Neurol 1961;5:202-9.

${ }^{18}$ Nashold BS Jr, Wilson WP, Slaughter DG. Sensations evoked by stimulation in the midbrain of man. $J$ Neurosurg 1969;30:14-24.

${ }^{19}$ Noordenbos W. Pain: Problems Pertaining to the Transmission of Nerve Impulses which Give Rise to Pain. New York: Elsevier, 1959.

${ }^{20}$ Spiegel EA, Wycis HT. Multiplicity of subcortical localization of various functions. J Nerv Ment Dis 1968;147:34-48. 